\title{
Copper Ferrite Superparamagnetic Nanoparticle- Catalyzed Cross-coupling Reaction to Form Diindolylmethane (DIM): Effect of Experimental Parameters
}

\author{
Oanh T.K. Nguyen ${ }^{1,2,3, *}$, Ha Trong Pha ${ }^{1,2}$, Huynh Dang Khoa ${ }^{1,2}$, Duy Chinh Nguyen ${ }^{3,4}$, \\ Nguyen Thi Hong Tham ${ }^{3,4}$
}

${ }^{1}$ Department of Chemical Engineering, Ho Chi Minh City University of Technology (HCMUT), 268 Ly

Thuong Kiet Street, District 10, Ho Chi Minh City 700000, Vietnam

${ }^{2}$ Vietnam National University Ho Chi Minh City, Linh Trung Ward, Thu Duc District, Ho Chi Minh City 700000, Vietnam

${ }^{3}$ NTT Hi-Tech Institute, Nguyen Tat Thanh University, Ho Chi Minh City 700000, Vietnam

${ }^{4}$ Center of Excellence for Green Energy and Environmental Nanomaterials (CE@GrEEN), Nguyen Tat Thanh University, Ho Chi Minh City 700000, Vietnam.

Received: 22 ${ }^{\text {nd }}$ June 2020; Revised: 23rd July 2020; Accepted: $31^{\text {st }}$ July 2020;

Available online: 14th August 2020; Published regularly: December 2020

\section{Abstract}

Superparamagnetic copper ferrite $\left(\mathrm{CuFe}_{2} \mathrm{O}_{4}\right)$ nanoparticles were utilized as a heterogenous catalyst for the cross-coupling reaction of indole to form 3,3'-diindolylmethane (DIM) as the desirable product. High reaction yield, at around $82 \%$, was achieved under optimal conditions. The $\mathrm{CuFe}_{2} \mathrm{O}_{4}$ material could be easily separated from the reaction mixture by an external magnetic field and could be reutilized several times without a significant decrease in catalytic activity. We also showed that no sites of catalyst material leached into reaction solution was detected. To our best knowledge, the above cross-coupling reaction was not previously conducted under catalysis of superparamagnetic nanoparticles. Copyright (C) 2020 BCREC Group. All rights reserved

Keywords: $\mathrm{CuFe}_{2} \mathrm{O}_{4}$; superparamagnetic nanoparticles; heterogeneous catalyst; cross-coupling reaction; 3,3'-diindolylmethane (DIM)

How to Cite: Nguyen, O.T.K., Pha, H.T., Khoa, H.D., Nguyen, D.C., Tham, N.T.H. (2020). Copper Ferrite Superparamagnetic Nanoparticle-Catalyzed Cross-coupling Reaction to Form Diindolylmethane (DIM): Effect of Experimental Parameters. Bulletin of Chemical Reaction Engineering \& Catalysis, 15(3), 631-640 (doi:10.9767/bcrec.15.3.8228.631-640)

Permalink/DOI: https://doi.org/10.9767/bcrec.15.3.8228.631-640

\section{Introduction}

3,3'-Diindolylmethane (DIM) is a dimeric product of 3-indolemethanol, generated from acidic medium and consists of bis-indole moiety

* Corresponding Author.

E-mail: kimoanhnguyen88@gmail.com (O.T.K. Nguyen)
[1]. DIM has been shown to hold potential applications in treatment of thyroid proliferative disease via promotion of estrogen metabolism [2] and in induction of apoptosis of prostate cancer cells in mouse model [3]. DIM is also an important metabolite that exhibits potential anticancer properties and is produced from the consumption of indole-3-carbinol, a compound cre- 
ated from the glycoside glucobrassicin, which widely exists in cruciferous vegetables such as broccoli, brussel sprouts, and cauliflower [4]. In addition, DIM was shown to possess multiple useful bioactivities including antioxidant [5], anti-inflammatory [6], antiangiogenic [7], and anticancer activities [8].

DIM was previously synthesized using different routines and catalysts. Chen et al. [9] and Qiang et al. [10] reported the production of DIM from indole in methanol solvent with the presence of homogeneous catalyst (Ir) in the air. Similarly, Zhang et al. [11] demonstrated that the derivative of DIM can be synthesized by using tetramethylethylenediamine (TMEDA) as a methylene corner supplier with $\mathrm{Cu}$ (II) catalyst reaction at $120{ }^{\circ} \mathrm{C}$, reflux module and MeCN solvent. Pu et al. [12] reported an efficient synthesis procedure in which indole ice DIM was produced with solvent of $N, N$ dimethylformamide (DMF), $10 \mathrm{~mol} \% \mathrm{CuCl}$ catalyst, temperature of $140{ }^{\circ} \mathrm{C}$ for 14 hours in the presence of tert-butyl hydroperoxide (TBHP) as an oxidant. Despite the high reaction efficiency and selectivity, all aforementioned studies utilized homogeneous catalysts in DIM production, presenting difficulty in catalyst recovery and going against the emergent trend of green chemistry.

Over the last years, research on nanoparticles of metal based materials has attracted much consideration due to their interesting properties, such as: superparamagnetism and ease of separability, and potential applications in a wide range of fields [13-15]. In the field of catalysis, copper ferrite nanoparticles have been used as a catalyst for a wide range of organic transformations [16-18]. Among these heterogeneous catalysts, functionalized metal oxide-based catalysts were used in most cases [19-21]. One notable application of copper ferrite has been reported by Prakash et al., in which $\mathrm{CuFe}_{2} \mathrm{O}_{4}$ nanoparticles were assembled on carbon nanotubes, affording a nanohybrid catalyst that facilely promoted the Huisgen 1,3cycloaddition of terminal alkynes with in situ generated organic azide under very mild operating conditions [22]. In another application, copper ferrite was doped with cerium to produce a nanocrystalline catalyst that was capable of inducing strong photodegradation of methyl orange under UV light [23]. It has been recently reported that unfunctionalized $\mathrm{CuFe}_{2} \mathrm{O}_{4}$ superparamagnetic nanoparticles could be also active in organic reactions with high catalytic activity and selectivity [24-26]. In our previous study, we developed a copper ferrite-catalyzed cross-coupling reaction that used TBHP as oxidant to form DIM and investigated the effects of various indole substituents on the reaction yield [27]. Continuing this research pathway, in this study, we wish to report a similar DIMforming dimeric reaction of indole and determined optimal experimental conditions (temperature, catalyst amount, solvent type, solvent amount, oxidant type and oxidant amount) that gave highest reaction yield.

\section{Materials and methods}

\subsection{Materials and Instrumentation}

Chemicals used in this study were commercially obtained and used as received without further purification. X-ray diffraction method (XRD) was measured on D8 advance device (Bruker) using $\mathrm{Cu}-\mathrm{K} \alpha$ emission source $(\lambda=$ $1.54 \AA)$. Recording of transmission electron microscopy images was carried out utilizing JEOL-JEM-1400 device at $80 \mathrm{kV}$.

Samples taken from reaction mixture were analyzed on Shimadzu GC 2010-Plus chromatograph using flame ionization detector (FID). The column used for analysis is SPB-5 column (length $30 \mathrm{~m} \times$ internal diameter 0.25 $\mathrm{mm} \times$ film thickness $0.25 \mu \mathrm{m}$ ). The temperature program for gas chromatographic analysis is as follows: the initial temperature was held at $100{ }^{\circ} \mathrm{C}$ for 1 minute, subsequently heated from $100{ }^{\circ} \mathrm{C}$ to $280{ }^{\circ} \mathrm{C}$ at $30^{\circ} \mathrm{C} / \mathrm{min}$ and then held again for 15 minutes. The injection chamber temperature was kept fixed at $280^{\circ} \mathrm{C}$. Diphenyl ether is used as an internal standard. NMR spectra $\left({ }^{1} \mathrm{H}\right.$ and $\left.{ }^{13} \mathrm{C}\right)$ were measured using Bruker AV 500 equipment operating at 500 $\mathrm{MHz}$ when measuring ${ }^{1} \mathrm{H}$ and at $125 \mathrm{MHz}$ when measuring ${ }^{13} \mathrm{C}$. The standard is Tetramethylsilane.

\subsection{Catalytic Studies}

In a typical experiment, the reaction is carried out in the reaction flask (special glass vial with a volume of $8 \mathrm{~mL}$ ). The mixture includes: $\mathrm{CuFe}_{2} \mathrm{O}_{4}$ catalyst $(0.05 \mathrm{mmol})$, indole $(0.5$ $\mathrm{mmol})$, internal standard diphenyl ether (0.025 $\mathrm{mmol})$, TBHP (1.5 mmol) as an oxidant, and $\mathrm{N}, \mathrm{N}$-dimethylacetamide (DMAC) $(1.5 \mathrm{~mL})$ as solvent. The flask was sealed in air and heated at $140{ }^{\circ} \mathrm{C}$ for 24 hours. The efficiency of the reaction was monitored by taking $0.1 \mathrm{~mL}$ of the reaction mixture after the reaction had completed and dissolving it with a mixture of solution including distilled water $(1 \mathrm{~mL})$ and ethyl acetate $(2 \mathrm{~mL})$. The ethyl acetate soluble fraction was anhydrous with $\mathrm{Na}_{2} \mathrm{SO}_{4}$ salt and ana- 
lyzed by GC. The structure of the product was characterized by GC-MS, ${ }^{1} \mathrm{H}-\mathrm{NMR}$, and ${ }^{13} \mathrm{C}$ NMR. The recyclability of $\mathrm{CuFe}_{2} \mathrm{O}_{4}$ was examined by removing the liquid phase of reaction mixture by an external magnetic field. The catalytic material was washed with large amounts of distilled water, ethanol, ethyl acetate, and acetone, separated by an external magnetic field, and dried under a vacuum at $150{ }^{\circ} \mathrm{C}$ for $180 \mathrm{~min}$. For investigation of leaching test, the synthesis reaction was stopped after one hour, analyzed by GC, and had catalytic material removed. The reaction mixture was then carried out for a further 7 hours. Reaction proceeding, if any, was controlled by GC analysis.

\section{Results and Discussions}

\subsection{Characterization of $\mathrm{CuFe}_{2} \mathrm{O}_{4}$ Catalyst}

The $\mathrm{CuFe}_{2} \mathrm{O}_{4}$ superparamagnetic nanoparticles were determined by various techniques. Figure 1 showed that XRD patterns of the $\mathrm{CuFe}_{2} \mathrm{O}_{4}$ are consistent with the standard XRD patterns JCPDS 01-077-0010 [28]. Transmission electron microscopy (TEM) revealed that most of the particles are spherical and have the size that is uniform and in the range of 20-50 $\mathrm{nm}$ (Figure 2).

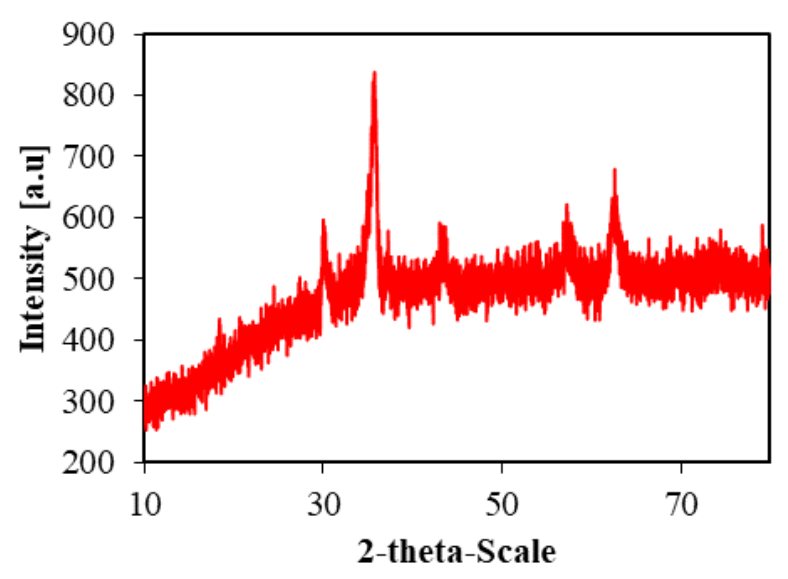

Figure 1. XRD diagram of the $\mathrm{CuFe}_{2} \mathrm{O}_{4}$.

\subsection{The Synthesis of 3,3'-diindolylmethane}

In the following optimization studies, the catalytic activity of $\mathrm{CuFe}_{2} \mathrm{O}_{4}$ material was determined in the cross-coupling reaction of indole in the DMAC solvent to form 3,3'diindolylmethane as the major product (Scheme 1). Its structure was determined by ${ }^{1} \mathrm{H}$ $\mathrm{NMR}$, and ${ }^{13} \mathrm{C}$ NMR. In this reaction, TBHP could be used as an oxidant.

Temperature is the first important factor that determines reaction yield. The reaction was performed in $1.5 \mathrm{~mL}$ DMAC solvent with

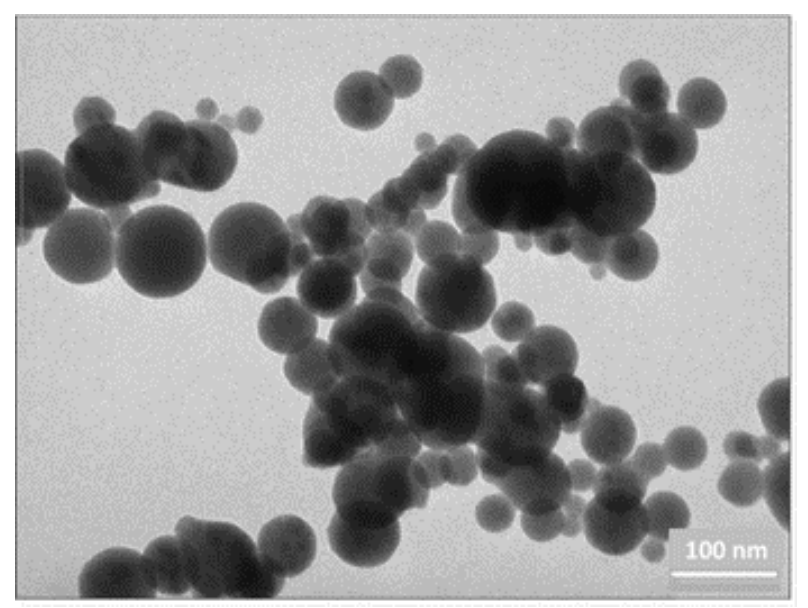

Figure 2. TEM micrograph of the $\mathrm{CuFe}_{2} \mathrm{O}_{4}$.

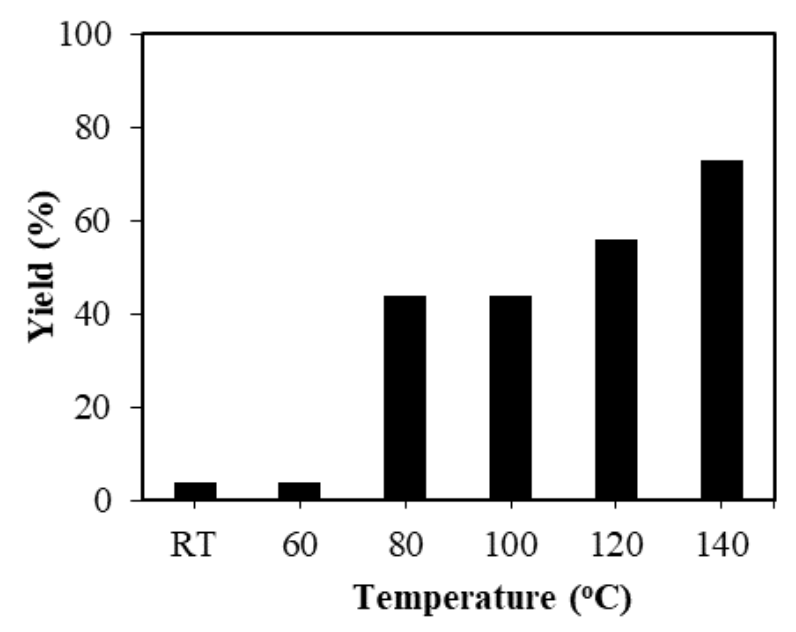

Figure 3. Effect of temperature on the reaction conversion.

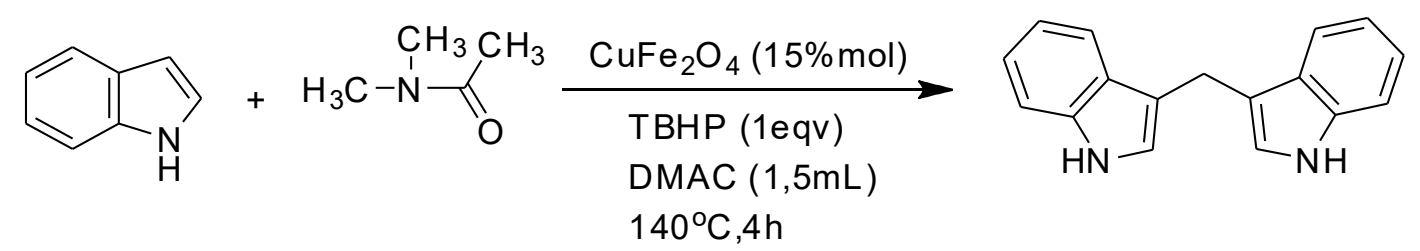

Scheme 1. The cross-coupling reaction of indole in $\mathrm{N}$, N-dimethylacetamide solvent using $\mathrm{CuFe}_{2} \mathrm{O}_{4}$ catalyst. 
indole ( $0.5 \mathrm{mmol})$, utilizing 3 equivalents TBHP as a oxidant for 24 hours, with $10 \mathrm{~mol} \%$ $\mathrm{CuFe}_{2} \mathrm{O}_{4}$ catalyst at varying temperatures including room temperature, $60,80,100,120$, and $140{ }^{\circ} \mathrm{C}$. From the Figure 3, it was shown that the reaction did not take place at temperature lower than $60^{\circ} \mathrm{C}$. At $80^{\circ} \mathrm{C}$ and $100{ }^{\circ} \mathrm{C}$, the reaction seemed to be relatively inefficient, resulting in reaction yields of around $45 \%$ after 24 hours. However, as the temperature was elevated to $140{ }^{\circ} \mathrm{C}$, an outstanding enhancement in reaction yield was observed, achieving around $77 \%$ yield after 24 hours. The temperature at which this reaction was previously carried out varied depending on the catalytic nature, ligand as well as the used substances. In particular, lower reaction temperature seemed to necessitate longer reaction time, which could be more than 48 hours [29]. Therefore, this reaction is considered as a high temperature re-

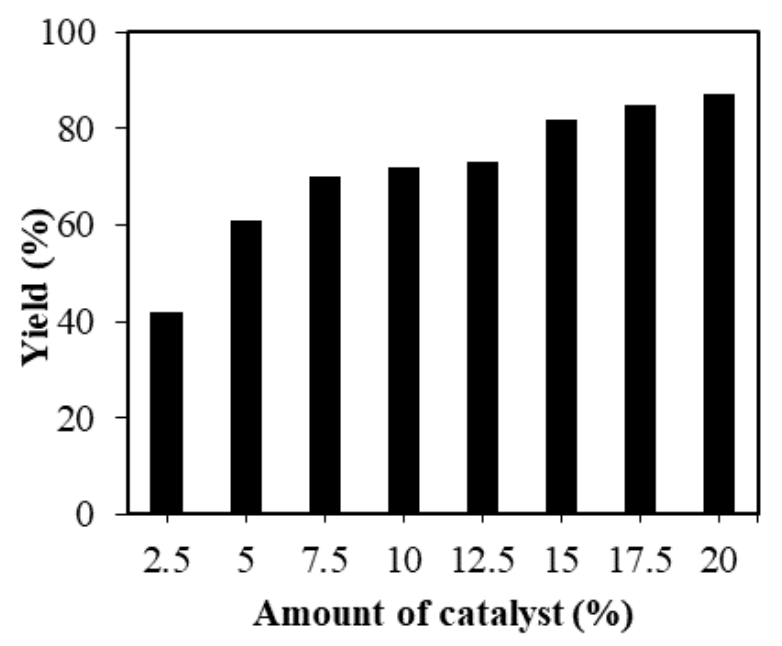

Figure 4. Effect of amount of catalyst the reaction conversion.

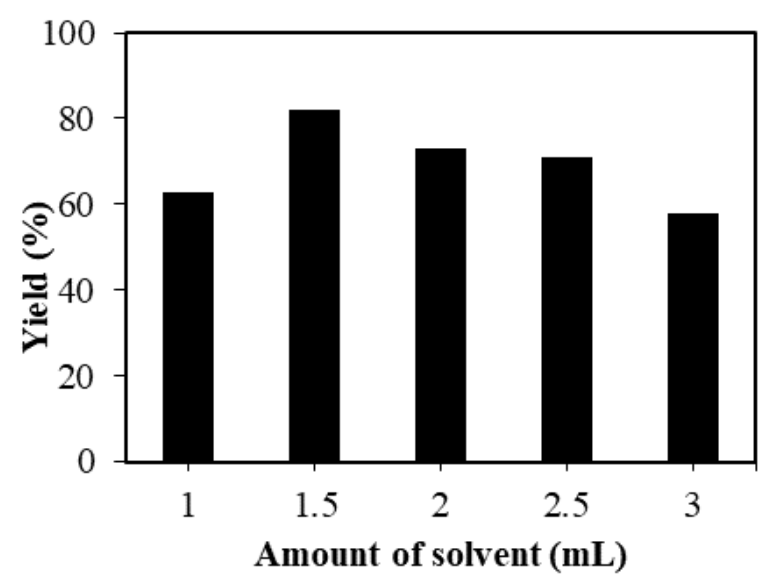

Figure 5. Effect of amount of solvent on the reaction conversion. action, usually performed in the temperature range of $110{ }^{\circ} \mathrm{C}$ to $160{ }^{\circ} \mathrm{C}$ for many different catalytic systems [12,30,31].

For an organic transformation utilizing a heterogenous catalyst, the amount of used catalyst is an important determinant of yield. The reaction was performed in $1.5 \mathrm{~mL}$ DMAC solvent with indole $(0.5 \mathrm{mmol})$, utilizing 3 equivalents TBHP as an oxidant at $140{ }^{\circ} \mathrm{C}$ for 24 hours, with the presence of varying amounts of $\mathrm{CuFe}_{2} \mathrm{O}_{4}$ catalyst of $2.5,5,7.5,10,12.5$ and 15 mol\% (Figure 4). It was observed that the catalyst quantity of $7.5 \mathrm{~mol} \%$ could afford $70 \%$ reaction yield, while up to $82 \%$ reaction yield was obtained with $15 \mathrm{~mol} \%$ of catalyst after 24 hours. The control experiment was performed without copper ferrite nanoparticles, resulting the reaction yield of around $7 \%$. Therefore, the amount of catalyst of $15 \mathrm{~mol} \%$ was selected as optimal. In fact, the used catalyst quantity of $15 \mathrm{~mol} \%$ is not very substantial and is very common for oxide-type catalysts. For example, copper-iron and copper oxide catalysts were previously used in organic synthesis with the amount ranging from 10 to $20 \mathrm{~mol} \%[17,32,33]$. Furthermore, the catalyst quantity of $15 \mathrm{~mol} \%$ is not considerably higher than those of studies that aim to form 3.3-Diindolylmethane compound with indole derivatives, including those involving homogeneous catalyst systems with complex ligands where a catalyst amount of 10 mol\% was still used [34,35].

The amount of used solvent is another crucial factor that also significantly affect the conversion and determination of optimal solvent use is essential to justify the economic efficiency of the reaction. The reaction was conducted at $140{ }^{\circ} \mathrm{C}$ in 24 hours, with the presence of 15 mol\% $\mathrm{CuFe}_{2} \mathrm{O}_{4}$ catalyst using 3 equivalents of

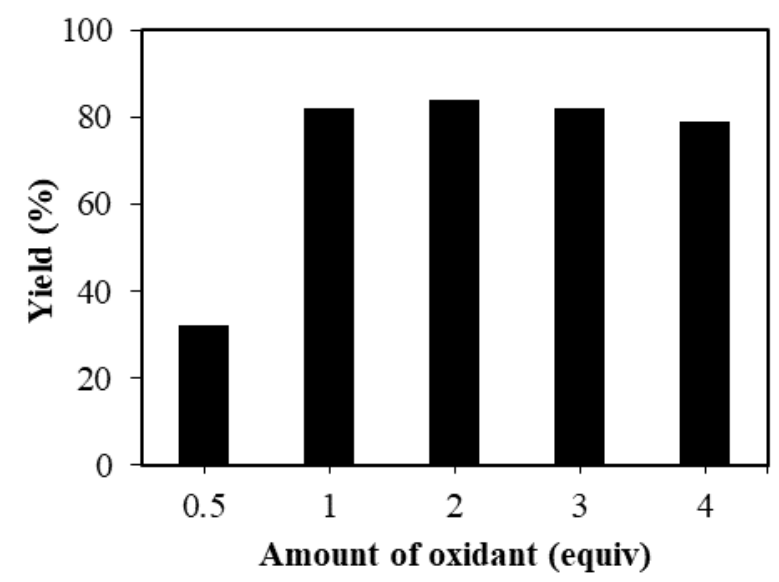

Figure 6. Effect of amount of oxidant on the reaction yield. 
TBHP as an oxidant and in the different solvent ratios of DMAC including 1, 1.5, 2, 2.5 and $3 \mathrm{~mL}$ (Figure 5). The results show that the solvent volume of $1.5 \mathrm{~mL}$ gave the highest efficiency of $82 \%$. Afterwards, increasing the volume of used solvent seemed to reduce the reaction yield. This suggests that $1.5 \mathrm{~mL}$ of solvent is optimal to efficiently convert $0.5 \mathrm{mmol}$ of indole through this reaction. The trend could be obviously explained by the reduced interaction of substances containing in the diluted reaction medium, which greatly affects the reaction efficiency. The reported solvent use in this study is consistent with results of most other studies on the synthesis of DIM compounds where the maximum quantity of the used solvent was 3 $\mathrm{mL}[35,36]$.

In the following survey, the amount of oxidant was examined with respect to reaction

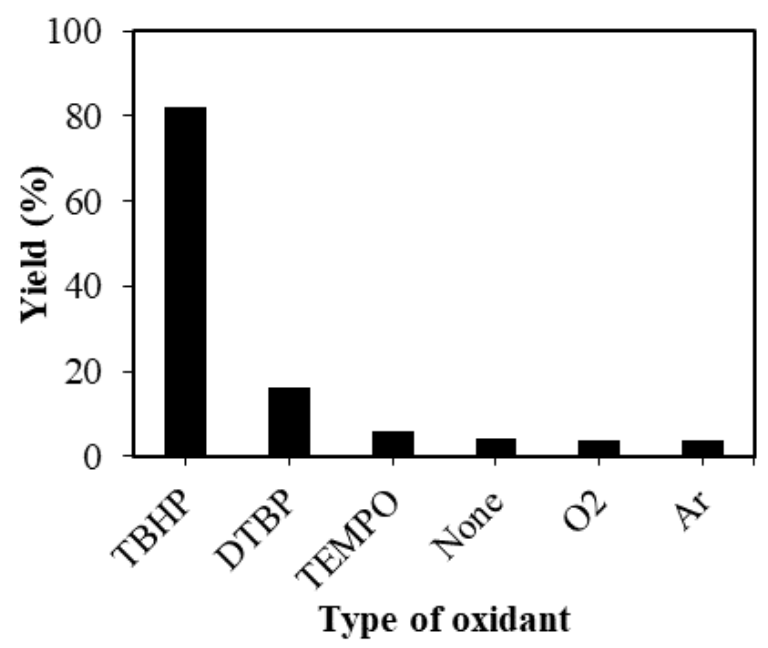

Figure 7. Effect of oxidant on the reaction yield.

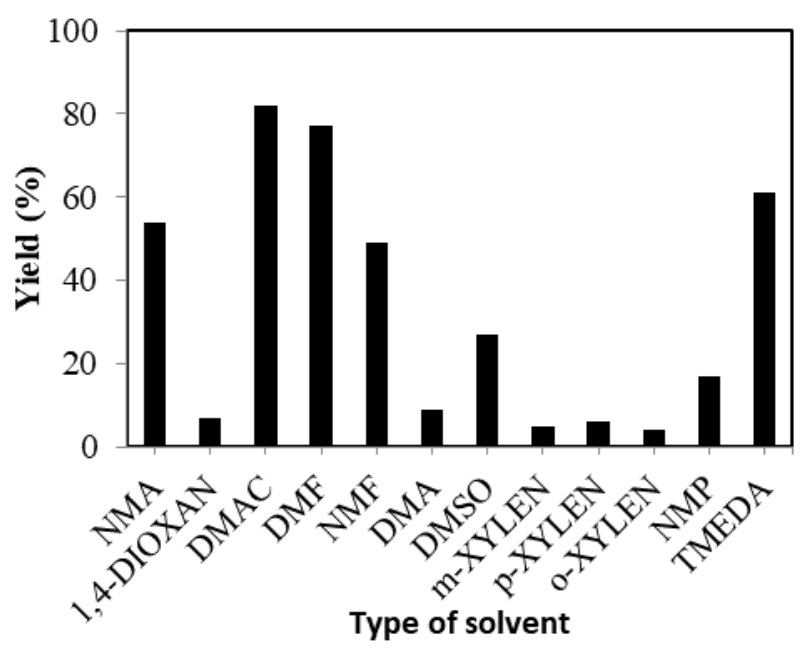

Figure 8. Effect solvent on the reaction conversion. yield. The reaction was performed at $140{ }^{\circ} \mathrm{C}$ for 24 hours, with $15 \mathrm{~mol} \% \mathrm{CuFe}_{2} \mathrm{O}_{4}$ catalyst, utilizing the various oxidant amounts of 0.5 equiv, 1 equiv, 2 equiv, 3 equiv, and 4 equiv (Figure 6). Noticeable improvement in yield was observed when increasing the TBHP amount from 0.5 to 1 equiv. However, increasing the amount of TBHP from 1 equiv to 2 equiv only caused the reaction yield to slightly improve by approximately $2 \%$. Therefore, the amount of oxidant used in the cross-coupling reaction was selected at around 1 equiv. This result is relatively consistent with some previous studies on DIM compounds [30,37]. In addition, the use of oxidant at a ratio of 1: 1 compared to indole was able to achieve almost complete conversion and selectivity up to $82 \%$ after 24 hours, so the investigation of the use of oxidant at larger concentrations is not strictly necessary.

To gain further insights into feasibility of the use of TBHP in this reaction, we compared the yields obtained using different oxidants in the following survey (Figure 7). The results showed that the reaction yield achieved when using TBHP, at $82 \%$, far surpassed that obtained using DTBP or 2,2,6,6 tetramethylpiperidinyl-1-oxyl (TEMPO). Additionally, the reaction did not seem to occur with $\mathrm{O}_{2}, \mathrm{Ar}$ or no oxidant. This is consistent with results of previous studies which indicated that the reaction only occurs with the presence of radicals as reaction intermediates $[12,34,36]$.

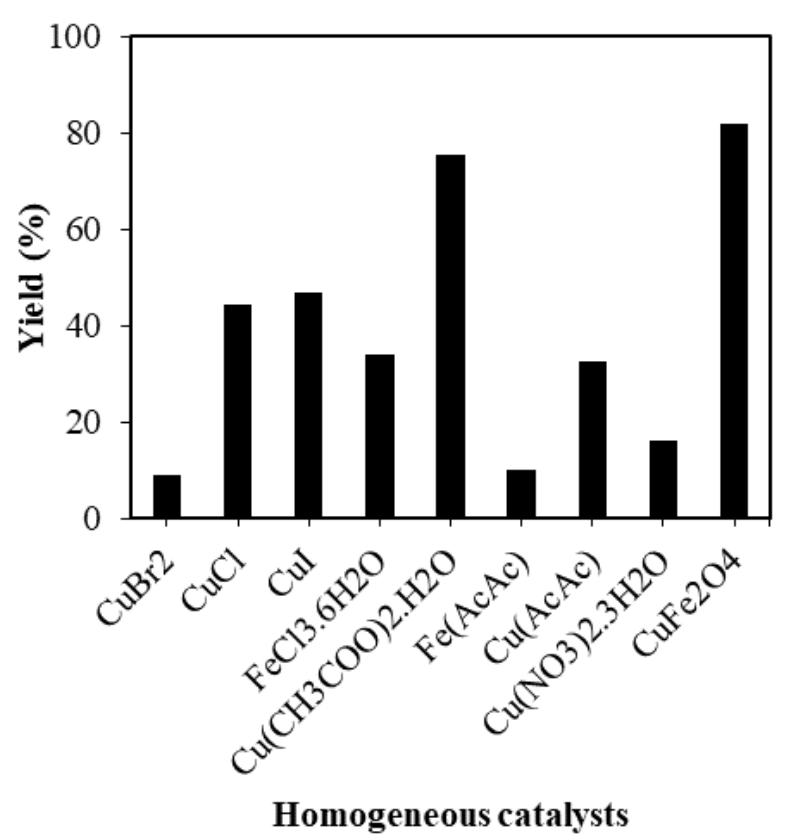

Figure 9. Effect of homogeneous catalysts on the reaction conversion. 
The effect of used solvent was examined by comparing yields obtained with different solvents. The synthetic reaction of DIM product was conducted at $140{ }^{\circ} \mathrm{C}$ in $1.5 \mathrm{~mL}$ of solvent for 24 hours, with $15 \mathrm{~mol} \% \mathrm{CuFe}_{2} \mathrm{O}_{4}$ catalyst using 1 equivalent of TBHP as an oxidant, with various solvents (Figure 8). The results showed that the performance varied greatly between different types of solvents. In general, polar solvents, such as: DMAC, DMF and $\gamma$-alumina (NMA), produced much higher efficiencies compared to less polar solvents, such as: 1,4dioxane, m-xylene and $\mathrm{p}$-xylene. The DMAC solvent gave the highest reaction efficiency of around $82 \%$ yield.

To justify the use of $\mathrm{CuFe}_{2} \mathrm{O}_{4}$ superparamagnetic nanoparticles in the reaction, we carried out the reaction at $140{ }^{\circ} \mathrm{C}$ in $1.5 \mathrm{~mL}$ of solvent for 24 hours, with the presence of various homogenous and heterogenous catalysts. The results shown in Figure 9 illustrated that among homogeneous catalysts, $\mathrm{Cu}\left(\mathrm{CH}_{3} \mathrm{COO}\right)_{2} \cdot \mathrm{H}_{2} \mathrm{O}$ gave the highest efficiency of $76 \%$. However, comparing with results of heterogenous catalysts, this yield was still lower than that achieved with $\mathrm{CuFe}_{2} \mathrm{O}_{4}$ catalyst, at $82 \%$. The results shown in Figure 10 also illustrated that other types of magnetic nanoparticle are not as effective as $\mathrm{CuFe}_{2} \mathrm{O}_{4}$ superparamagnetic nanoparticle in catalyzing the crosscoupling reaction. It is worth noting that all examined metal-organic framework (MOF) materials resulted in very high yields in which the outstanding efficiency, at $91 \%$, was achieved when using MOF-199. However, the use of

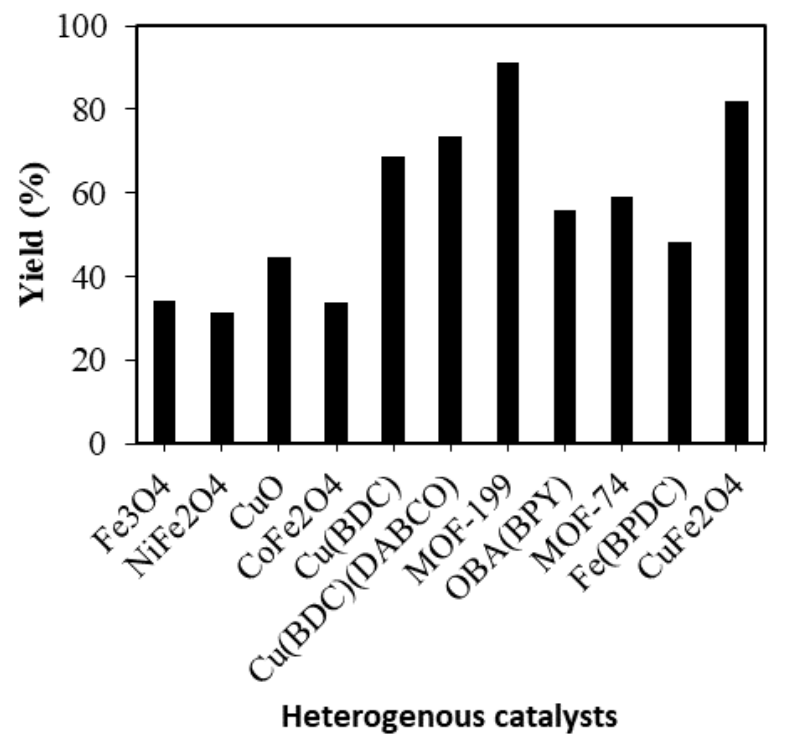

Figure 10. Effect of heterogenous catalysts on the reaction yield.
MOFs is not in line with the objective of this study, which is to identify a catalyst that is environmentally friendly, re-recyclable, highly heat-resistant and easily recoverable with an external magnetic field. Moreover, it is speculated that MOF materials often exhibit poorer thermal stability than magnetic materials. As such, as the reaction was carried out under elevated temperatures, part of the material core and ligand existing in the reaction media may impair the reaction efficiency. Based on the heterogeneous catalyst property, $\mathrm{CuFe}_{2} \mathrm{O}_{4}$ material is a suitable catalyst for reaction in this study.

The dissolution of active sites on the heterogenous catalyst into the solution occurring during the reaction might affect recoverability, selectivity and reusability of the used catalyst. To determine whether the dissolution of active sites of the $\mathrm{CuFe}_{2} \mathrm{O}_{4}$ catalyst contributed to the generation of desired product, an experiment under optimal conditions was performed with the magnetic separation of catalyst (leaching test). The reaction was carried out at $140{ }^{\circ} \mathrm{C}$ in DMAC solvent for 24 hours, utilizing indole $(0.5 \mathrm{mmol})$ with one equivalent of TBHP as oxidant and the presence of $15 \mathrm{~mol}^{2} \mathrm{CuFe}_{2} \mathrm{O}_{4}$ catalyst. After 60 minutes reaction time, the DMAC phase was separated from the reaction solution by an external magnetic field, transferred to a new round bottom flask, which was heated for 7 hours at $140{ }^{\circ} \mathrm{C}$. As indicated in the graph (Figure 11), generation of 3,3'-diindolylmethane ceased after the $\mathrm{CuFe}_{2} \mathrm{O}_{4}$ catalyst had been removed from the reaction

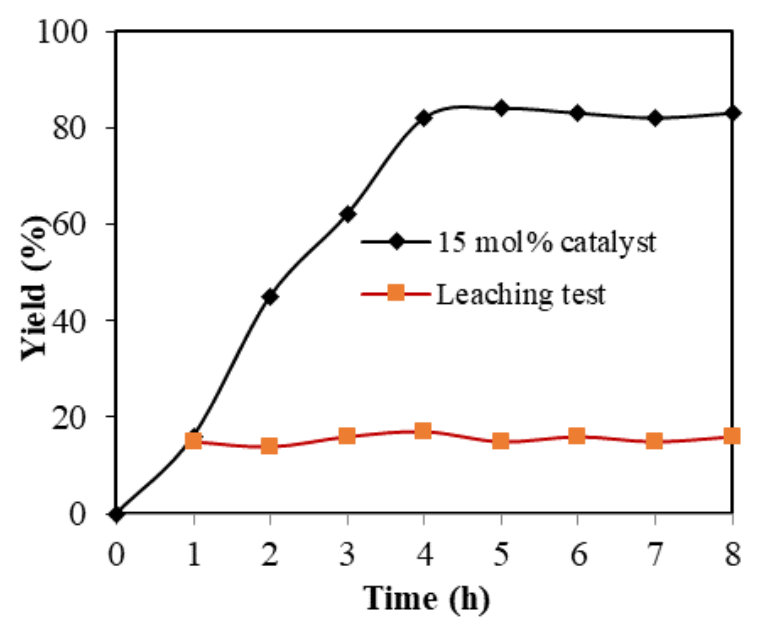

Figure 11. Leaching test showing no contribution from homogeneous catalyst of active species leaching into reaction solution. 
mixture at the one-hour mark. These results indicated that presence of the $\mathrm{CuFe}_{2} \mathrm{O}_{4}$ catalyst is a prerequisite for this reaction to take place and the leaching of active copper species into the solution was almost nonexistent, thus making no significant contribution to the yield.

To justify organic reactions utilizing heterogeneous catalysts in development of more environmentally benign processes, the facileness of separation as well as the recoverability and reusability of the catalysts should be taken into account. The $\mathrm{CuFe}_{2} \mathrm{O}_{4}$ was therefore studied for the recoverability and reusability in the crosscoupling reaction. The reaction was performed at $140{ }^{\circ} \mathrm{C}$ in DMAC solvent for 24 hours, using indole $(0.5 \mathrm{mmol})$ with one equivalent of TBHP as an oxidant, with $15 \mathrm{~mol}_{0} \mathrm{CuFe}_{2} \mathrm{O}_{4}$ catalyst. After the first run, the $\mathrm{CuFe}_{2} \mathrm{O}_{4}$ catalyst was removed from the reaction solution by an external magnetic field, washed with large amounts of distilled water, ethanol, ethyl acetate, and acetone to remove any physisorbed reagents, dried at $140^{\circ} \mathrm{C}$ under vacuum in $180 \mathrm{~min}$, and reutilized in further reactions with conditions identical to those of the first run. It was illustrated that the $\mathrm{CuFe}_{2} \mathrm{O}_{4}$ catalyst could be recovered and reutilized nine times in the crosscoupling reaction without significant compromise of catalytic activity. Evidently, the yield of 3,3'-diindolylmethane still reached $74 \%$ after eight runs, which is 8 percent point lower than the yield achieved at the first run (Figure 12). The recoverability of the $\mathrm{CuFe}_{2} \mathrm{O}_{4}$ catalysts before and after nine runs was illustrated by XRD diffractograms (Figure 13), indicating that crystal morphology of the $\mathrm{CuFe}_{2} \mathrm{O}_{4}$ material was almost unchanged after eight times of reuse.

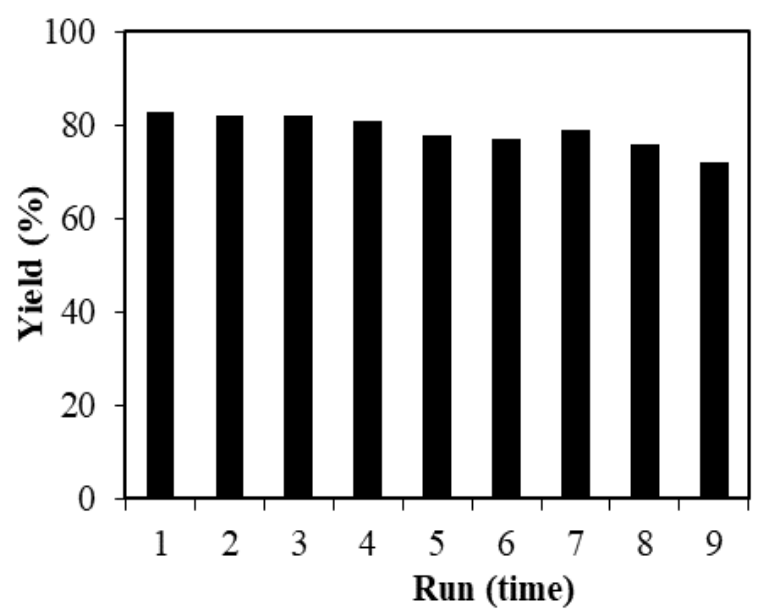

Figure 12. Catalyst recycling studies.

\section{Conclusion}

In this study, the $\mathrm{CuFe}_{2} \mathrm{O}_{4}$ nanoparticles were used as heterogeneous catalyst for the cross-coupling reaction of indole to create 3,3'diindolylmethane as the major product. The optimal conditions that gave the highest yield consisted of TBHP as oxidant in DMAC solvent, temperature of $140{ }^{\circ} \mathrm{C}$, reaction time of 24 hours and catalyst quantity of $15 \mathrm{~mol} \%$. The $\mathrm{CuFe}_{2} \mathrm{O}_{4}$ demonstrated higher catalytic activity in the cross-coupling reaction than other magnetic heterogeneous catalysts, such as: $\mathrm{CoFe}_{2} \mathrm{O}_{4}, \mathrm{NiFe}_{2} \mathrm{O}_{4}, \mathrm{Fe}_{3} \mathrm{O}_{4}$, and $\mathrm{Fe}_{2} \mathrm{O}_{3}$. We also further confirmed that the reaction could only proceed to create 3,3'-diindolylmethane in the presence of the $\mathrm{CuFe}_{2} \mathrm{O}_{4}$ catalyst and that the contribution from leached active sites of the $\mathrm{CuFe}_{2} \mathrm{O}_{4}$ catalyst was negligible. Furthermore, the $\mathrm{CuFe}_{2} \mathrm{O}_{4}$ nanoparticles could be easily removed from the reaction solution by an external magnetic field and could be reutilized for nine times with only minor loss of catalytic activity.

\section{Acknowledgement}

We would like to give my sincerest thank to Department of Chemical Engineering, Ho Chi Minh City University of Technology for providing us with facilities and chemicals to carry out experiments.

\section{Author Contributions}

Investigation, Oanh Nguyen T. K., Trong Pha Ha, Dang Khoa Huynh and Hong Tham Nguyen Thi; Supervision, Van Tan Lam; Writing - original draft, Oanh Nguyen T. K.; Writing - review \& editing, Duy Chinh Nguyen.

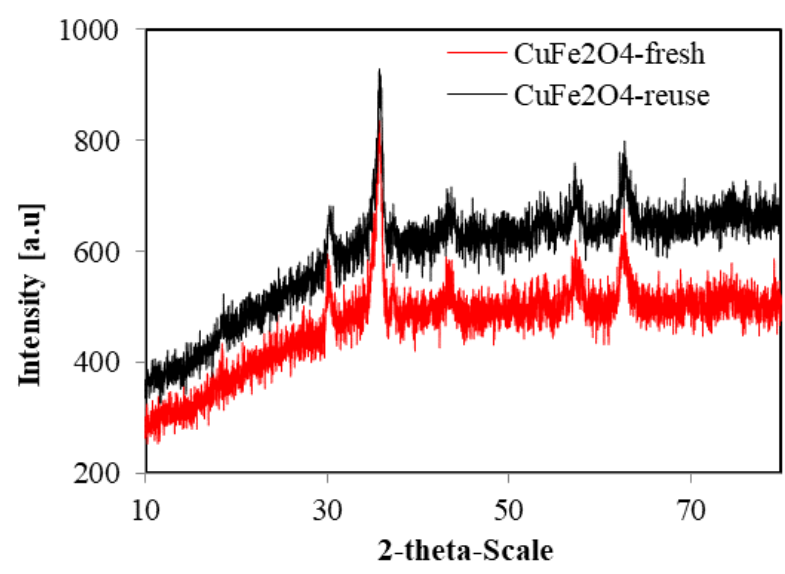

Figure 13. X-ray powder diffractograms of the $\mathrm{CuFe}_{2} \mathrm{O}_{4}$ fresh (red) and $\mathrm{CuFe}_{2} \mathrm{O}_{4}$ reutilizing (black). 


\section{References}

[1] Roy, S., Gajbhiye, R., Mandal, M., Pal, C., Meyyapan, A., Mukherjee, J., Jaisankar, P. (2014). Synthesis and antibacterial evaluation of $3,3^{\prime}$-diindolylmethane derivatives. Medicinal Chemistry Research, 23(3), 1371-1377. DOI: 10.1007/s00044-013-0737-7

[2] Rajoria, S., Suriano, R., Parmar, P.S., Wilson, Y.L., Megwalu, U., Moscatello, A., Bradlow, H.L., Sepkovic, D.W., Geliebter, J., Schantz, S.P., Tiwari, R.K. (2011). 3, 3' diindolylmethane modulates estrogen metabolism in patients with thyroid proliferative disease: A pilot study. Thyroid, 21(3), 299304. DOI: 10.1089/thy.2010.0245

[3] Cho, H.J., Park, S.Y., Kim, E.J., Kim, J.-K., Park, J.H.Y. (2011). 3,3'-diindolylmethane inhibits prostate cancer development in the transgenic adenocarcinoma mouse prostate model. Molecular Carcinogenesis, 50(2), 100112. DOI: $10.1002 / \mathrm{mc} .20698$

[4] Zhang, W. W., Feng, Z., Narod, S.A. (2014). Multiple therapeutic and preventive effects of 3,39-diindolylmethane on cancers including prostate cancer and high grade prostatic intraepithelial neoplasia. Journal of Biomedical Research. 28 (5), 339-348. DOI: 10.7555/JBR.28.20140008

[5] Jayakumar, P., Pugalendi, K.V., Sankaran, M. (2014). Attenuation of hyperglycemiamediated oxidative stress by indole-3-carbinol and its metabolite 3,3'-diindolylmethane in C57BL/6J mice. Journal of Physiology and Biochemistry, 70(2), 525-534. DOI: 10.1007/s13105-014-0332-5

[6] Cho, H.J., Seon, M.R., Lee, Y.M., Kim, J., Kim, J.-K., Kim, S.G., Park, J.H.Y. (2008). $3,3^{\prime}$-diindolylmethane suppresses the inflammatory response to lipopolysaccharide in murine macrophages. The Journal of Nutrition, 138(1), 17-23. DOI: 10.1093/jn/138.1.17

[7] Kunimasa, K., Kobayashi, T., Kaji, K., Ohta, T. (2010). Antiangiogenic effects of indole-3carbinol and 3,3'-diindolylmethane are associated with their differential regulation of erk1/2 and akt in tube-forming huvec. The Journal of Nutrition, 140(1), 1-6. DOI: 10.3945/jn.109.112359

[8] Zong, J., Wu, Q.-Q., Zhou, H., Zhang, J.-Y., Yuan, Y., Bian, Z.-Y., Deng, W., Dai, J., Li, F.F., Xu, M., Fang, Y., Tang, Q.-Z. (2015). 3,3'Diindolylmethane attenuates cardiac $\mathrm{H} 9 \mathrm{c} 2$ cell hypertrophy through 5 '-adenosine monophosphate-activated protein kinasea. Molecular Medicine Reports, 12(1), 12471252. DOI: $10.3892 / \mathrm{mmr} .2015 .3523$
[9] Chen, S.-J., Lu, G.-P., Cai, C. (2015). Iridiumcatalyzed methylation of indoles and pyrroles using methanol as feedstock. RSC Advances, 5(86), 70329-70332. DOI: 10.1039/C5RA15822B

[10] Qiang, W., Liu, X., Loh, T.-P. (2019). Supported iridium catalyst for the green synthesis of $3,3^{\prime}$-bis(Indolyl)methanes using methanol as the bridging methylene source. ACS Sustainable Chemistry \& Engineering, 7(9), 84298439. DOI: 10.1021/acssuschemeng.9b00094

[11] Zhang, L., Peng, C., Zhao, D., Wang, Y., Fu, H.-J., Shen, Q., Li, J.-X. (2012). Cu(Ii)catalyzed C-H (sp3) oxidation and C-N cleavage: Base-switched methylenation and formylation using tetramethylethylenediamine as a carbon source. Chemical Communications, 48(47), 5928. DOI: $10.1039 / \mathrm{c} 2 \mathrm{cc} 32009 \mathrm{f}$

[12] Pu, F., Li, Y., Song, Y.-H., Xiao, J., Liu, Z.-W., Wang, C., Liu, Z.-T., Chen, J.-G., Lu, J. (2016). Copper-catalyzed coupling of indoles with dimethylformamide as a methylenating reagent. Advanced Synthesis \& Catalysis, $358(4), \quad 539-542$. D O I : 10.1002/adsc.201500874

[13] Phan, N.T.S., Gill, C.S., Nguyen, J.V., Zhang, Z.J., Jones, C.W. (2006). Expanding the utility of one-pot multistep reaction networks through compartmentation and recovery of the catalyst. Angewandte Chemie International Edition, 45(14), 2209-2212. DOI: 10.1002/anie.200503445

[14] Hudson, R., Ishikawa, S., Li, C.-J., Moores, A. (2013). Magnetically recoverable cufe2o4 nanoparticles as highly active catalysts for csp3csp and $\operatorname{csp} 3-\operatorname{csp} 3$ oxidative crossdehydrogenative coupling. Synlett, 24(13), 1637-1642. DOI: 10.1055/s-0033-1339278

[15] Sivakami, R., Babu, S.G., Dhanuskodi, S., Karvembu, R. (2015). Magnetically retrievable lepidocrocite supported copper oxide nanocatalyst $(\mathrm{Fe}-\mathrm{CuO})$ for N-arylation of imidazole. RSC Advances, 5(12), 8571-8578. DOI: 10.1039/C4RA13256D

[16] Polshettiwar, V., Luque, R., Fihri, A., Zhu, H., Bouhrara, M., Basset, J.-M. (2011). Magnetically recoverable nanocatalysts. Chemical Reviews, 111(5), 3036-3075. DOI: $10.1021 / \operatorname{cr} 100230 \mathrm{z}$

[17] Yang, D., Zhu, X., Wei, W., Jiang, M., Zhang, N., Ren, D., You, J., Wang, H. (2014). Magnetic copper ferrite nanoparticles: An inexpensive, efficient, recyclable catalyst for the synthesis of substituted benzoxazoles via Ullmann-type coupling under ligand-free conditions. Synlett., 25(05), 729-735. DOI: 10.1055/s-0033-1340599 
[18] Satish, G., Reddy, K.H.V., Ramesh, K., Kumar, B.S.P.A., Nageswar, Y.V.D. (2014). An elegant protocol for the synthesis of $\mathrm{N}$ substituted pyrroles through $\mathrm{C}-\mathrm{N}$ cross coupling/aromatization process using $\mathrm{CuFe} 2 \mathrm{O} 4$ nanoparticles as catalyst under ligand-free conditions. Tetrahedron Letters, 55(16), 25962599. DOI: 10.1016/j.tetlet.2014.01.075

[19] Lu, A.-H., Salabas, E.L., Schüth, F. (2007). Magnetic nanoparticles: Synthesis, protection, functionalization, and application. Angewandte Chemie International Edition, 46(8), 1222-1244. DOI: 10.1002/anie.200602866

[20] Vásquez-Céspedes, S., Holtkamp, M., Karst, U., Glorius, F. (2017). Reusable and magnetic palladium and copper oxide catalysts in direct ortho and meta arylation of anilide derivatives. Synlett., 28(20), 2759-2764. DOI: 10.1055/s-0036-1589007

[21] Zhang, W., Tian, Y., Zhao, N., Wang, Y., Li, J., Wang, Z. (2014). Nano CuO-catalyzed C-H functionalization of 1,3 -azoles with bro$\mathrm{mo}$ a re $\mathrm{nes}$ a n d bromo a l kenes. Tetrahedron, 70(36), 6120-6126. DOI: 10.1016/j.tet.2014.04.065

[22] Prakash, P., Kumar, R.A., Miserque, F., Geertsen, V., Gravel, E., Doris, E. (2018). Carbon nanotube-copper ferrite-catalyzed aqueous 1,3-dipolar cycloaddition of in situ generated organic azides with alkynes. Chemical Communications, 54(29), 3644-3647. DOI: 10.1039/C8CC00231B

[23] Rahimi-Nasrabadi, M., Behpour, M., SobhaniNasab, A., Jeddy, M.R. (2016). Nanocrystalline Ce-doped copper ferrite: Synthesis, characterization, and its photocatalyst application. Journal of Materials Science: Materials in Electronics, 27(11), 11691-11697. DOI: 10.1007/s10854-016-5305-8

[24] Al-Hunaiti, A., Al-Said, N., Halawani, L., Haija, M.A., Baqaien, R., Taher, D. (2020). Synthesis of magnetic $\mathrm{CuFe}_{2} \mathrm{O}_{4}$ nanoparticles as green catalyst for toluene oxidation under solvent-free conditions. Arabian Journal of Chemistry, 13(4), 4945-4953. DOI: 10.1016/j.arabjc.2020.01.017

[25] Nguyen, O.T.K., Nguyen, L.T., Truong, N.K., Nguyen, V.D., Nguyen, A.T., Le, N.T.H., Le, D.T., Phan, N.T.S. (2017). Synthesis of triphenylamines via ligand-free selective ringopening of benzoxazoles or benzothiazoles under superparamagnetic nanoparticle catalysis. RSC Advances, 7(65), 40929-40939. DOI: 10.1039/C7RA06168D

[26] Nguyen, O.T.K., Ha, P.T., Dang, H.V., Vo, Y.H., Nguyen, T.T., Le, N.T.H., Phan, N.T.S. (2019). Superparamagnetic nanoparticlecatalyzed coupling of 2 -amino pyri- dines/pyrimidines with trans -chalcones. RSC Advances, 9(10), 5501-5511. DOI: 10.1039/C9RA00097F

[27] Ha, P., Nguyen, O., Huynh, K., Nguyen, T., Phan, N. (2018). Synthesis of unnatural arundines using a magnetically reusable copper ferrite catalyst. Synlett, 29(15), 2031-2034. DOI: $10.1055 / \mathrm{s}-0037-1610227$

[28] Tasca, J.E., Ponzinibbio, A., Diaz, G., Bravo, R.D., Lavat, A., González, M.G. (2010). $\mathrm{CuFe}_{2} \mathrm{O}_{4}$ nanoparticles: A magnetically recoverable catalyst for selective deacetylation of carbohydrate derivatives. Topics in Catalysis, 53(15-18), 1087-1090. DOI: 10.1007/s11244010-9538-0

[29] Pillaiyar, T., Gorska, E., Schnakenburg, G., Müller, C.E. (2018). General Synthesis of Unsymmetrical 3,3'-(Aza)diindolylmethane Derivatives. The Journal of Organic Chemistry, $83(17), \quad 9902-9913$. D O I : 10.1021/acs.joc.8b01349

[30] Kaswan, P., Nandwana, N.K., DeBoef, B., Kumar, A. (2016). Vanadyl acetylacetonate catalyzed methylenation of imidazo[1,2a]pyridines by using dimethylacetamide as a methylene source: Direct access to bis(Imidazo[1,2-a]pyridin-3-yl)methanes. $A d$ vanced Synthesis \& Catalysis, 358(13), 21082115. DOI: 10.1002/adsc.201600225

[31] Deb, M.L., Borpatra, P.J., Pegu, C.D., Thakuria, R., Saikia, P.J., Baruah, P.K. (2017). Iodine/ tert -butyl hydroperoxide-mediated reaction of indoles with dimethylformamide/dimethylacetamide to synthesize bisand tris(Indolyl)methanes. ChemistrySelect, 2(1), 140-146. DOI: 10.1002/slct.201601857

[32] Panda, N., Jena, A.K., Mohapatra, S., Rout, S.R. (2011). Copper ferrite nanoparticlemediated N-arylation of heterocycles: A ligand-free reaction. Tetrahedron Letters, 52(16), 1924-1927. DOI: 10.1016/j.tetlet.2011.02.050

[33] Rosario, A.R., Casola, K.K., Oliveira, C.E.S., Zeni, G. (2013). Copper oxide nanoparticlecatalyzed chalcogenation of the carbonhydrogen bond in thiazoles: Synthesis of 2(Organochalcogen)thiazoles. Advanced Synthesis \& Catalysis, 355(14-15), 2960-2966. DOI: $10.1002 / \mathrm{adsc} .201300497$

[34] Deb, M.L., Borpatra, P.J., Saikia, P.J., Baruah, P.K. (2017). Introducing tetramethylurea as a new methylene precursor: A microwave-assisted $\mathrm{RuCl}_{3}$-catalyzed cross dehydrogenative coupling approach to bis(Indolyl)methanes. Organic \& Biomolecular Chemistry, 15(6), 1435-1443. DOI: 10.1039/C6OB02671K 
[35] Modi, A., Ali, W., Patel, B.K. (2016). N,n dimethylacetamide (DMA) as a methylene synthon for regioselective linkage of imidazo[1,2-a]pyridine. Advanced Synthesis \& Catalysis, 358(13), 2100-2107. DOI: 10.1002/adsc.201600067

[36] Mondal, S., Samanta, S., Santra, S., Bagdi, A. K., Hajra, A. (2016). n,n-dimethylformamide as a methylenating reagent: Synthesis of heterodiarylmethanes via copper-catalyzed coupling between imidazo[1,2-a]pyridines and indoles/n,n-dimethylaniline. Advanced Synthesis \& Catalysis, 358(22), 3633-3641. DOI: 10.1002/adsc.201600674
[37] Srivastava, A., Agarwal, A., Gupta, S.K., Jain, N. (2016). Graphene oxide decorated with $\mathrm{Cu}(\mathrm{I}) \mathrm{Br}$ nanoparticles: A reusable catalyst for the synthesis of potent bisme(Indolyl)thane based anti HIV drugs. RSC Advances, 6(27), 23008-23011. DOI: $10.1039 / \mathrm{C} 6 \mathrm{RA} 02458 \mathrm{~K}$ 